\title{
Penentuan Karakteristik Tremor Gunungapi Semeru Jawa Timur Berdasarkan Analisis Spektral (Studi Kasus: Oktober 2015-Desember 2015)
}

\author{
Dea Hertiara Municha ${ }^{1, *}$, Mimin Iryanti ${ }^{2}$, Hetty Triastuty ${ }^{1}$ \\ ${ }^{1}$ Departemen Pendidikan Fisika,Universitas Pendidikan Indonesia \\ Jl. Dr. Setiabudhi No. 299 Bandung 40154 \\ ${ }^{2}$ Pusat Vulkanologi Mitigasi dan Bencana Geoglogi (PVMBG ) \\ Jl. Jalan Dipenogero No 57, Bandung \\ Email:deahertiaramunicha@gmail.com h.triastuty@gmail.com
}

\begin{abstract}
ABSTRAK
Gunungapi Semeru merupakan salah satu gunung aktif di Indonesia dengan tipe erupsi vulkanian dan strombolian. Penelitian ini menggunakan data seismik digital G. Semeru yang terekam pada bulan Oktober 2015- Desember 2015. Data yang akan digunakan dalam penelitian ini yaitu data tremor vulkanik gunungapi Semeru. Penelitian ini bertujuan untuk mengetahui perubahan aktivitas vulkanik yang berdasarkan pada perubahan kegiatan tremor vulkanik. Tremor vulkanik merupakan gempa yang sering terjadi di sekitar gunungapi, gempa ini terjadi akibat aktivitas pergerakan magma ke atas di dalam gunungapi. Salah satu cara untuk mengetahui karakteristik aktivitas Gunung Semeru yaitu dengan analisis spektral. Analisis spektral ini dilakukan dengan menerapkan Fast Fourier Transform. Tujuan dari transformasi ini adalah untuk merubah sinyal dari domain waktu ke domain frekuensi sehinggal diperoleh spektrum frekuensi dari sinyalsinyal vulkanik. Berdasarkan analisis spektral pada gunung Semeru ini didominasi tremor harmonik yang memiliki ciri-ciri bentuk sinyal puncak spektral yang teratur serta memiliki frekuensi dasar tremor harmonik berkisar $0.1 \mathrm{~Hz}-2 \mathrm{~Hz}$, sedangkan frekuensi dominan tremor harmonik berkisar $0.2 \mathrm{~Hz}-3.5 \mathrm{~Hz}$, serta kandungan frekuensi tremor G. Semeru tergolong rendah. Serta terjadi perubahan tertinggi frekuensi dasar dan frekuensi dominan pada stasiun Puncak.
\end{abstract}

Kata kunci : analisis spektral, tremor vulkanik, gunungapi Semeru. 


\begin{abstract}
Semeru Volcano is one of the active volcanoes in Indonesia with the types of volcanian and strombolian eruptions. This research used digital seismic data of Semeru Volcano that had been recorded on October 2015 to December 2015. The data used in this research was data volcanic tremor of Semeru volcano. This study aimed to determine the changes in volcanic activities based on changes in volcanic tremor activities. Volcanic tremors are frequent earthquakes that are occurred around volcanoes, these earthquakes occurred due to magma movements upward in the volcano. One way to characterize the activity of Semeru Volcano is using spectral analysis. Spectral analysis is conducted by applying a Fast Fourier Transform. The purpose of this transformation is to change the signal from the time domain to the frequency domain, so that it will obtain frequency spectrum from volcanic signals. Data processing on this research was done by running spectrogram, the selection of waveform and then analyzed based on spectral analysis. Based on spectral analysis on Semeru Volcano, it is dominated harmonic tremor which possess the characteristics of the shape of the spectral peak signal which is regular as well as the basic harmonic tremor which has a frequency range of $0.1 \mathrm{~Hz}-2 \mathrm{~Hz}$, whereas the dominant frequency of harmonic tremor range 0.1 $\mathrm{Hz}-3.5 \mathrm{~Hz}$, and frequency content of tremor Semeru volcano belongs to low. In addition, occurred highest frequency of changes as well as basic and dominant frequencies at Puncak station.
\end{abstract}

Keywords: spectral analysis, volcanic tremors, Semeru volcano.

\section{PENDAHULUAN}

Gunungapi Semeru merupakan gunungapi aktif di Jawa Timur, dengan ketingian $3676 \mathrm{~m}$ diatas permukaan laut (dpl). G. Semeru secara administratif termasuk dalam wilayah Kabupaten Lumajang dan Kabupaten Malang, Propinsi Jawa Timur. Secara geografis terletak pada posisi $8^{\circ} 06^{\prime} 5^{\prime}$ ' LS dan $112^{\circ} 55^{\prime}$ BT dengan puncak tertinggi Mahameru $3676 \mathrm{~m} \mathrm{dpl}$ (diatas permukaan laut) yang merupakan tempat tertinggi di Pulau Jawa. Aktivitas Gunungapi Semeru ditandai dengan seringnya terekamnya aktivitas gempa-gempa vulkanik yang terkait dengan intensitas yang cukup tinggi gempa letusan, hembusan dan tremor harmonik. (Dinas ESDM Jawa Timur, 2010). Letusan G. Semeru umumnya bertipe campuran antara vulkanian dan strombolian. Letusan tipe vulkanian dicirikan dengan letusan eksplosif yang dapat menghancurkan kubah dan lidah lava yang telah terbentuk sebelumnya. Selanjutnya terjadi letusan bertipe strombolian yang biasanya diikuti dengan pembentukan kubah dan lidah lava baru. Pada saat terjadi letusan eksplosif biasanya dikuti oleh terjadinya aliran awan panas yang mengalir ke lembah-lembah yang lebih rendah. 
Tremor vulkanik merupakan gelombang seismik yang biasa teramati di dekat gunungapi aktif dan dapat menjadi indikasi terjadinya letusan. Gejala ini berhubungan dengan gerakan yang terjadi di bawah permukaan akibat aliran magma. Salah satu terori yang mengajukan pemodelan dari proses tremor vulkanik menyatakan bahwa tremor muncul karena ketidakstabilan pipa konduit akibat interaksi antara aliran magma dengan batuan disekitarnya (Julian, 1994 dalam Neli dkk). Tremor vulkanik dibagi menjadi dua yaitu tremor vulkanik dan tremor spasmodik. Tremor harmonik memiliki ciri-ciri kenampakan sinyal dan bentuk spektrum yang teratur (berbentuk sinusoidal) sedangakan tremor spasmodik memiliki ciri-ciri kenampakan sinyal dan bentuk spektrum yang tidak teratur. Kegiatan ini merupakan sebuah pertanda peningkatan aktivitas vulkanik di dalam kubah magma (lava dome) pada sebuah gunungapi.

Terdapat kegiatan seismik pada G. Semeru yang pertama yaitu keadaaan dimana sebelum terjadi letusan, ditandai dengan tidak adanya bentuk sinyal dengan amplitudo besar. Kedua yaitu keadaan terjadi letusan, ditandai dengan puncak sinyal yang tidak teratur dan amplitudo besar. Ketiga yaitu keadaan sesudah letusan, ditandai dengan bentuk sinyal harmonik dengan frekuensi rendah, dan amplitudo besar (Kirbani dkk 1992).
Gunungapi Semeru mempunyai frekuensi tremor harmonik sangat rendah yaitu antara $1.0 \mathrm{~Hz}$ samai 4.0 $\mathrm{Hz}$ dengan frekuensi dasar berkisar $0.8 \mathrm{~Hz}$ sampai $1.3 \mathrm{~Hz}$. Kedalaman tremor harmonik terjadi pada kedalaman antara $2.5 \mathrm{~km}$ sampai 3.5 km (Yatini, 1995).

Pada penelitian ini, difokuskan pada tremor vulkanik G. Semeru dengan melakukan analisis spektral merupakan metode yang berguna dalam mengetahui pola aktivitas vulkanik gunungapi berdasarkan spektrum frekuensi sinyal seismik. Keuntungan analisis dalam kawasan frekuensi, antara lain yaitu perhitungan matematis dalam kawasan frekuensi lebih mudah diterapkan dibandingkan dengan dalam kawasan waktu, fenomena geofisika pada umumnya dalam bentuk ketergantungan terhadap frekuensi, sehingga dalam beberapa fenomena fisik, frekuensi menjadi parameter yang sangat penting dalam menjelaskan fenomena tersebut (Welayatur, 2013). Spektrum frekuensi dapat diketahui dengan menerapkan FFT (Fast Fourier Transform) pada data seismik gunungapi.

\section{METODE PENELITIAN}

Gunungapi Semeru mempunyai aktivitas yang sangat tinggi. Letusannya bertipe strombolian dan vulkanian. Letusan tipe vulkanian dicirikan dengan letusan eksplosif yang kadang-kadang menghancurkan 
kubah dan lidah lava yang telah terbentuk sebelumnya. Selanjutnya terjadi letusan bertipe strombolian yang biasanya diikuti dengan pembentukan kubah dan lidah lava baru. Aktivitas G. Semeru saat ini terdapat di Kawah Jonggring Seleko yang terletak di sebelah tenggara puncak Mahameru yang terbentuk sejak 1913. Sejak tahun 1964 hingga saat ini, aktvitas letusannya tidak pernah berhenti. Letusan terjadi setiap interval 15 menit hingga 1 jam, dengan tinggi asap letusan berkisar antara 400-800 meter. Jumlah rata-rata gempa letusan perhari 90 kali kejadian. Pada saat terjadinya letusan eksplosif biasanya diikuti oleh terjadinya aliran awan panas yang mengalir ke lembahlembah yang lebih rendah dana rah alirannya sesuai dengan bukaan kawah dan lembah-lembah di G. Semeru. Arah bukaan kawah G. Semeru saat ini mengarah kea rah tenggara atau mengarah ke hulu Besuk Bang, Besuk Kembar dan Besuk Kebokan.

Tremor Vulkanik Tremor vulkanik merupakan salah satu jenis sinyal seismik yang sering ditemukan di sekitar gunungapi, kemunculannya juga dapat dijadikan indikasi adanya letusan. Secara umum tremor vulkanik memiliki karakteristik waktu yang lama dan amplitudonya bervariasi, selain itu tremor vulkanik juga memiliki karakteristik onset time yang tidak jelas sehingga waktu tiba tremor vulkanik tidak bisa diketahui. Dalam domain frekuensi, tremor vulkanik menunjukan variasi yang berbeda, hal ini berkaitan dengan sumber dari tremor dan efek propogasi sinyal selama penjalarannya. Frekuensi tremor vulkanik biasanya berkisar antara $0,5-7 \mathrm{~Hz}$ dan bentuk spektrumnya biasanya dicirikan oleh satu atau beberapa puncak yang yang harmonik, atau bentuk spektrum dengan distribusi puncak yang acak. Variasi temporal dari frekuensi tremor vulkanik disinyalir merupakan efek dari sumbernya (Gottschammer, 1998).

Pada metode seismic surface wave merupakan gelombang noise yang harus dihilangkan. Menurut Macelwane dan Schon (1932) dalam Seismogram Analysis (1960) Surface wave terdapat dua jenis, yaitu:

a) Gelombang Reylegh (Reylegh wave). Gelombang Reyleigh merupakan gelombang permukaan yang orbit gerakannya elips tegak lurus dengan permukaan dan arah penjalarannya

b) Gelombang Love (Love wave). Gelombang cinta atau love wave merupakan gelombang yang menjalar di permukaan bumi yang karakteristiknya memiliki pergerakan yang mirip dengan gelombang $\mathrm{S}$, yaitu arah partikel medan yang dilewati arahnya tegak lurus terhadap arah perambatan gelombang, yang membedakan adalah lokasi perambatan love wave terdapat di permukaan bumi dan getarannya secara lateral (mendatar).

Mekanisme penjalaran gelombang seismik didasarkan pada hukum Snellius, Prinsip Huygens, dan Prinsip Fermat. Penjelasan dari 
hukum Snellius, Prinsip Huygens, dan Prinsip Fermat dijelaskan sebagai berikut:

- Hukum Snellius

Ketika gelombang seismik melalui lapisan batuan dengan impedansi akustik yang berbeda dari lapisan batuan yang dilalui sebelumnya, maka gelombang akan terbagi. Gelombang tersebut sebagian terefleksikan kembali ke permukaan dan sebagian diteruskan merambat dibawah permukaan.

- Prinsip Huygens

Prinsip Huygens menyatakan bahwa setiap titik pada muka gelombang merupakan sumber bagi gelombang baru. Posisi dari muka gelombang dalam dapat seketika ditemukan dengan membentuk garis singgung permukaan untuk semua wavelet sekunder.

- Prinsip Fermat

Gelombang menjalar dari satu titik ke titik lain melalui jalan tersingkat waktu penjalarannya.

Dengan demikian jika gelombang melewati sebuah medium yang memiliki variasi kecepatan gelombang seismik, maka gelombang tersebut akan cenderung melalui zona-zona kecepatan tinggi dan menghindari zona-zona kecepatan rendah (Jamady, 2011).

Data yang digunakan dalam penelitian ini adalah data sekunder dan merupakan data rekaman sinyal seismik Gunungapi Semeru yang diperoleh dari pos pengamatan gunungapi Semeru. Data terdiri atas rekaman sinyal seismik selama 3 bulan yaitu bulan Oktober, November, dan Desember 2015. Dengan memfokuskan pada tremor harmonik saja.

Analisa data yang dilakukan yaitu analisis spektral dan spektogram. Pada tahapan analisis spektral dilakukan untuk mendapatkan frekuensi sinyal-sinyal tremor harmonik gunungapi Semeru. Sebelumnya dilakukan seleksi data terlebih dahulu dengan memilih sinyal pada beberapa stasiun yaitu Puncak, Kepolo, Leker, Tretes, dan Besuk Bang. Analisis spektral dilakukan dengan metode Fast Fourier Transform (FFT), dimana sebelum dilakukan analisis spektral terlebih dahulu dilakukan pemotongan data yang bertujuan untuk memperoleh spectrum sinyal yang diinginkan. Dimana dalam proses pemotongan datanya sama dengan $2^{\mathrm{n}}$ dan pada penelitian ini dipilih $\mathrm{n}=11$ sehingga ada 2048 data yang diambil seperti pada gambar 2.2. Sedangkan pada tahapan Running Spektogram dilakukan untuk melihat dominasi frekuensifrekuensi dari tremor vulkanik terhadap waktu terjadinya tremor vulkanik seperti pada gambar

Analisis spektral dalam seismologi menggunakan algoritma Tranformasi Fourier. Transformasi Fourier adalah transformasi dari domain waktu ke domain frekuensi. Transformasi fourier dari suatu fungsi $f(t)$ didefinisikan pada persamaan 


$$
\begin{gathered}
F(\omega)=\int_{-\infty}^{\infty} f(t) e^{-i \omega t} d t \\
\varnothing(\omega)=\tan ^{-1}\left[-\frac{b(\omega)}{a(\omega)}\right]+2 n \pi
\end{gathered}
$$

dengan :

$$
\begin{array}{ll}
F(\omega) & =\text { spektral } \\
a(\omega) & =\text { variabel riil } \\
b(\omega) & =\text { variabel imajiner } \\
A(\omega) & =\text { spektrum amplitudo } \\
\varnothing(\omega) & =\text { spektrum fase } \\
\omega & =\text { frekuensi sudut }(\mathrm{rad} / \mathrm{s}) \\
f & =\text { frekuensi }(\mathrm{Hz})
\end{array}
$$
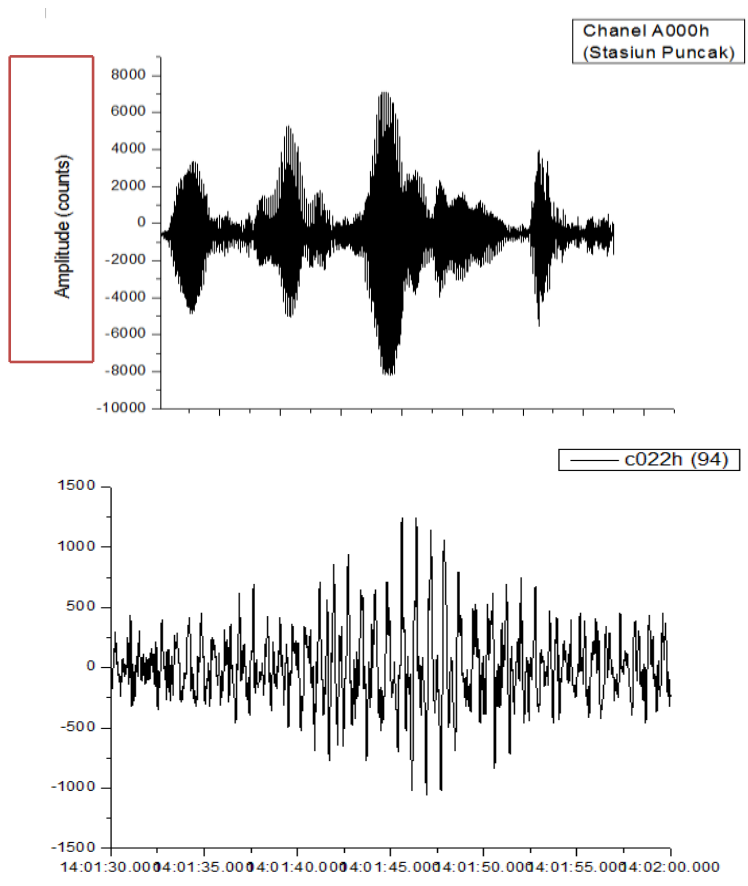

Gambar 1. Proses pemotongan data

(a) yang akan dipotong (b) Hasil data yang telah dipotong 


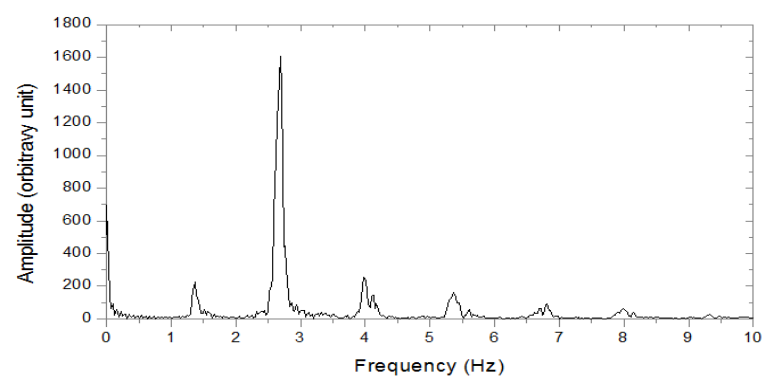

Gambar 2. Hasil FFT

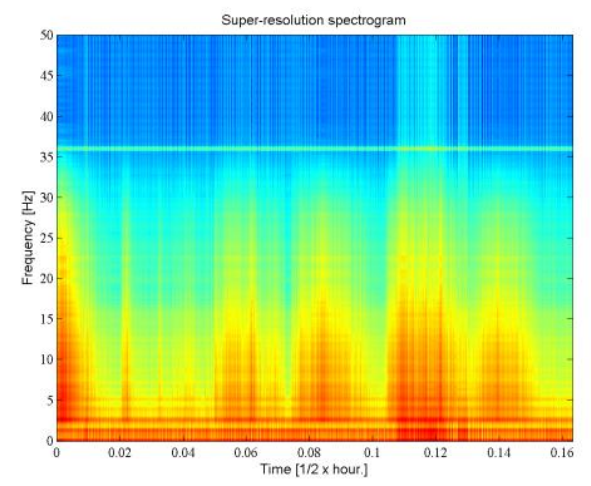

Gambar 3. Hasil Spektogram

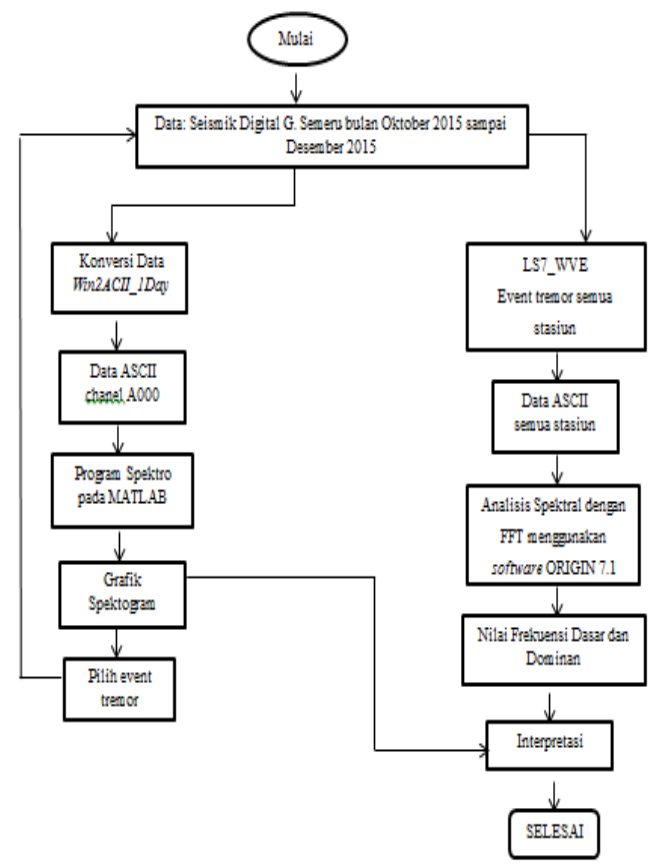

Gambar 4. Diagram Alur Penelitian 


\section{ANALISIS DAN PEMBAHASAN}

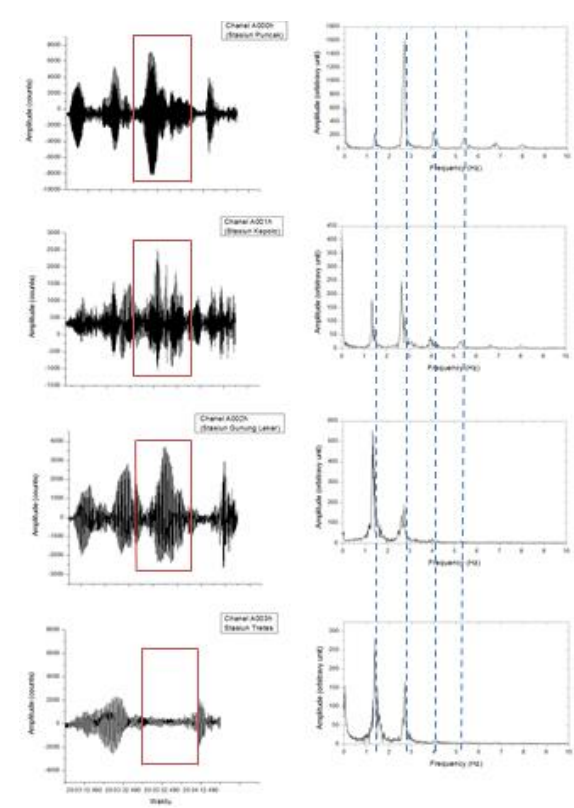

Gambar 5. Hasil FFT Event Tremor Harmonik Tanggal 14 November 2015 pukul 20:02:57 WIB

(a) Stasiun Puncak (b) Stasiun Kepolo (c) Stasiun Gunung Leker (d) Stasiun Tretes

Gambar 5 memperlihatkan seismogram dan spektogram tremor harmonik yang terjadi pada tanggal 14 November 2015 pukul 20:02:57 WIB. Frekuensi tremor hasil analisis spektral pada Gambar 4.4 terdapat 4 puncak dengan frekuensi berbedabeda. Pada stasiun Puncak hasil FFT menunjukan nilai frekuensi awal sebesar $1.37 \mathrm{~Hz}$, dan frekuensi selanjutnya bernilai $2.65 \mathrm{~Hz}, 3.96$ $\mathrm{Hz}$, dan $5.32 \mathrm{~Hz}$, dengan nilai frekuensi dominan $2.65 \mathrm{~Hz}$. Kemudian hasil FFT pada stasiun Kepolo memiliki frekuensi awal sebesar $1.34 \mathrm{~Hz}$ serta nilai frekuensi selanjutnya bernilai $2.65 \mathrm{~Hz}, 3.96$
$\mathrm{Hz}$, dan $5.32 \mathrm{~Hz}$, dengan frekuensi dominan sebesar $2.56 \mathrm{~Hz}$. Hasil FFT untuk stasiun Gunung Leker menunjukan nilai frekuensi awal sebesar $1.32 \mathrm{~Hz}$ serta nilai frekuensi selanjutnya bernilai $2.62 \mathrm{~Hz}, 3.95$ $\mathrm{Hz}$, dan 5.25, dengan nilai frekuensi dominan sebesar $1.32 \mathrm{~Hz}$. Pada stasiun terakhir yaitu stasiun Tretes hasil FFT menunjukan nilai frekuensi awal sebesar $1.34 \mathrm{~Hz}$ dan nilai frekuensi selanjutnya sebesar $2.69 \mathrm{~Hz}, 3.99 \mathrm{~Hz}$, dan $5.01 \mathrm{~Hz}$, dengan frekuensi dominan sebesar $1.34 \mathrm{~Hz}$. 


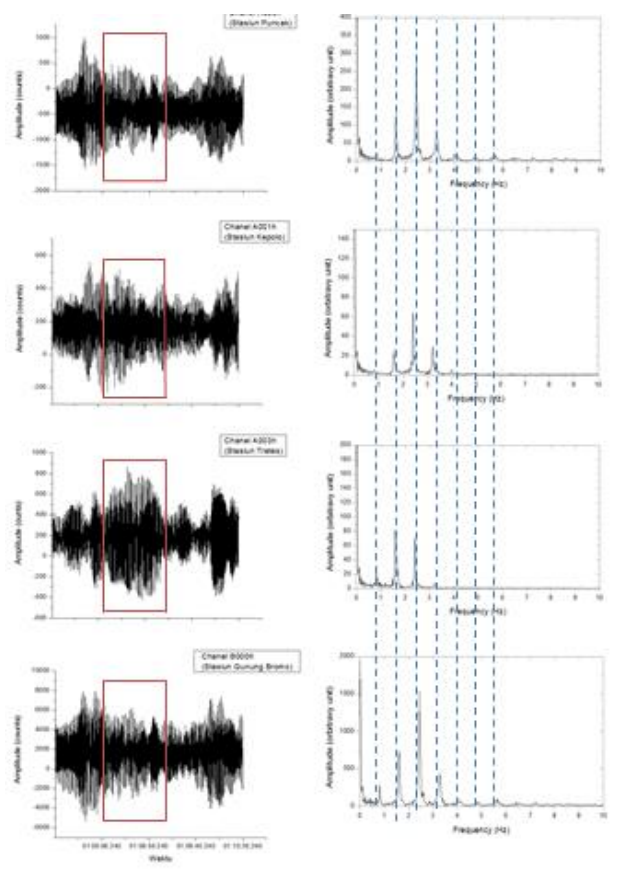

Gambar 6. Hasil FFT Event Tremor Harmonik Tanggal 01 November 2015 pukul 01:07:37

(a) Stasiun Puncak (b) Stasiun Kepolo (c) Stasiun Tretes (d) Stasiun Gunung Bromo

Gambar 6 menunjukkan spektral hasil rekaman tremor pada tanggal 01 November 2015 pukul 01:07:37 terdapat 4 stasiun dengan 5 puncak frekuensi yang berbeda-beda. Pada stasiun Puncak hasil FFT menunjukan nilai frekuensi awal sebesar $0.79 \mathrm{~Hz}$, dan frekuensi selanjutnya bernilai $1.58 \mathrm{~Hz}, 2.44$ $\mathrm{Hz}, 3.29 \mathrm{~Hz}, 4.01,4.87$, dan 5.87 $\mathrm{Hz}$, dengan frekuensi dominan sebesar $2.44 \mathrm{~Hz}$. Untuk hasil FFT pada stasiun Kepolo memiliki nilai frekuensi awal sebesar $0.81 \mathrm{~Hz}$, dengan frekuensi lainnya sebesar $1.58 \mathrm{~Hz}, 2.41 \mathrm{~Hz}, 3.22 \mathrm{~Hz}, 3.99 \mathrm{~Hz}$ dan frekuensi dominan sebesar 2.41 Hz. Hasil FFT di stasiun Tretes menunjukan nilai frekuensi awal sebesar $0.81 \mathrm{~Hz}$, serta nilai frekuensi selanjutnya bernilai $1.73 \mathrm{~Hz}, 2.55$ $\mathrm{Hz}, 3.25 \mathrm{~Hz}$, dan $4 \mathrm{~Hz}$, dengan frekuensi dominan bernilai $1.58 \mathrm{~Hz}$. Dan pada stasiun Gunung Bromo hasil FFT menunjukan nilai frekuensi awal sebesar $0.79 \mathrm{~Hz}$, frekuensi selanjutnya bernilai 1.60 $\mathrm{Hz}, 2.41 \mathrm{~Hz}, 3.18 \mathrm{~Hz}$, dan $4.02 \mathrm{~Hz}$, dengan nilai frekuensi dominan sebesar 2.41 Hz. Dari keempat stasiun, 2 diantaranya mempunyai frekuensi dasar yang sama yaitu pada stasiun Puncak dan stasiun Gunung Bromo, serta stasiun Kepelo dan stasiun Tretes, hal ini menunjukan bahwa sumber tremor harmonik ini berasal dari sumber yang sama. Terlihat dari keempat stasiun ini 
memiliki pola yang teratur karena sekitar $0.8 \mathrm{~Hz}$. frekuensi yang dihasilkan bergeser

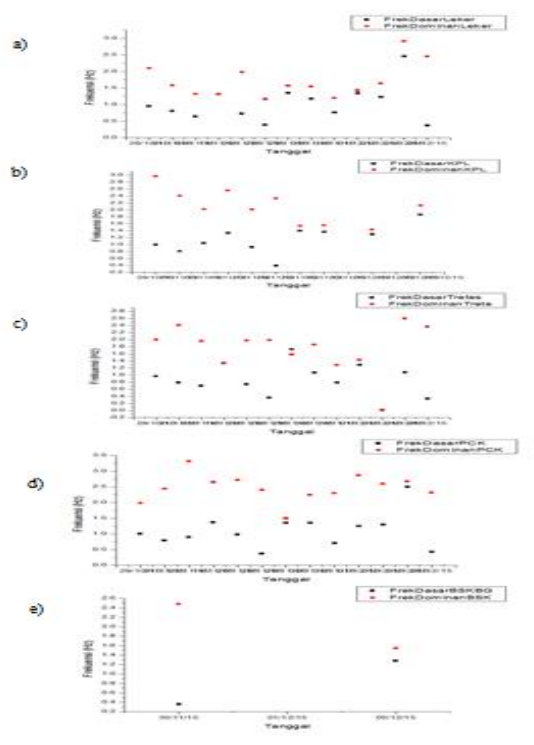

Gambar 7. Grafik Frekuensi Dasar dan Dominan

(a) Stasiun Leker (b) Stasiun Kepolo (c) Stasiun Tretes (d) Stasiun Puncak (e) Stasiun Besuk Bang

Pada gambar 8 (a), (b), (c), dan (d) terlihat kenaikan dan penurunan kandungan tremor pada setiap stasiun. Kenaikan frekuensi ini berkaitan dengan kecepatan struktur batuan yang semakin besar karena kubah lava yang terus naik ke permukaan. Kubah lava yang sebelumnya kosong karena kecepatan struktur semakin besar maka kubah lava tersebut terus terisi oleh material magma. Dengan demikian peningkatan lava flux dan kecepatan struktur batuan pada gunungapi akan mempengaruhi nilai frekuensi. Sedangkan penurunan frekuensi kemungkinan disebabkan oleh akumulasi tekanan gas yang masih cukup rendah, sehingga penghancuran kubah lava belum intensif.

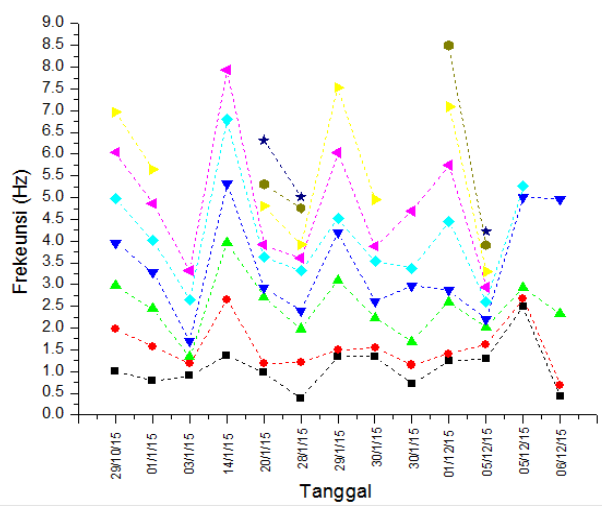


Gambar 8. Grafik puncak-puncak frekuensi di Stasiun Puncak

Dengan asumsi semua peak muncul di stasiun Puncak, penulis mengambil data pada stasiun puncak karena pada stasiun ini sangat jarang ditemukan noise sehingga dipilihlah stasiun Puncak sebagai acuannya. Hasil pengamatan diperoleh bahwa harga-harga puncak frekuensi memiliki kelipatan yang hampir sama mengikuti persamaan $f n=n * f o$ dengan $f n$ sebagai frekuensi ke- $n$; $f o$ adalah frekuensi dasar dan $n$ data ke$0,1,2$, dan seterusnya. Untuk event tremor yang sama, direkam oleh stasiun yang berbeda menghasilkan spektra yang sama. Hal ini menunjukan bahwa fenomena yang terekam merupakan pencerminan proses sumber bukan efek penjalaran gelombang dari sumber menuju masing-masing.

Sebagai contoh adalah spektral harmonik G. Semeru pada stasiun puncak tanggal 28 Oktober 2015 pukul 12:00:15 memiliki puncakpuncaknya sebesar $1.01 \mathrm{~Hz}, 1.98 \mathrm{~Hz}$, $2.97 \mathrm{~Hz}, 3.96 \mathrm{~Hz}, 4.97 \mathrm{~Hz}$, dan 6.04 Hz. Dengan nilai frekuensi dasar sebesar $1.07 \mathrm{~Hz}$. Selain itu pada tanggal 1 November 2015 pukul 01:07:37 mempunyai puncak-puncak sebesar $0.79 \mathrm{~Hz}, 1.58 \mathrm{~Hz}, 2.44 \mathrm{~Hz}$, $3.29 \mathrm{~Hz}, 4.01 \mathrm{~Hz}$, dan 4.87. Sedangkan pada tanggal 14 November 2015 pukul 20:02:57 memiliki puncak-puncak frekuensi sebesar $1.37 \mathrm{~Hz}, 2.65 \mathrm{~Hz}, 3.96 \mathrm{~Hz}$, $3.96 \mathrm{~Hz}, 5.32 \mathrm{~Hz}, 6.79 \mathrm{~Hz}$, dan 7.94 Hz. Dengan mengikuti persamaan $f n=n * f_{o}$ dan $n=1, \quad 2,3, \quad$ dan seterusnya maka $f_{1}=1 \mathrm{~Hz}, f_{2}=2 \mathrm{~Hz}$, $f_{3}=3 \mathrm{~Hz}$ dan seterusnya. Terjadi pergeseran pada puncak-puncak frekuensi dengan nilai hampir mendekati dengan pola kelipatan seperti persamaan $f n=n * f o$, hal ini menunjukan bahwa sumber tremor harmonik ini berasal dari sumber yang sama. Terjadinya perubahan tekanan fluida yang menyebabkan terjadinya pergeseran. Namun pada tanggal 1 November 2015 dan 14 November pergeseran puncak frekuensi dengan mengikuti persamaan $f n=n * f o$ menunjukan perubahan yang sedikit lebih besar dan terjadinya pergeseran yang lebih besar dikarenakan perubahan kelakuan batuan dinding saluran.

\section{SIMPULAN}

Berdasarkan hasil pengolahan data yang telah dilakuakan didapat simpulan sebagai berikut:

Tremor vulkanik yang ada pada gunung Semeru ini didominasi tremor harmonik yang memiliki ciri-ciri bentuk sinyal puncak spektral yang teratur serta memiliki frekuensi dasar tremor harmonik berkisar $0.1 \mathrm{~Hz}-2 \mathrm{~Hz}$, sedangkan frekuensi dominan tremor harmonik berkisar $0.2 \mathrm{~Hz}$ $3.5 \mathrm{~Hz}$, serta kandungan frekuensi tremor G. Semeru tergolong rendah.

$\begin{array}{lr}\text { Penelitian } & \text { selanjutnya } \\ \text { diharapkan } & \text { mampu } \\ \text { menjelaskan } & \text { dan } \\ \text { menganalisis } & \text { hiposenter } \\ \text { sehingga dapat } & \text { diketahui }\end{array}$




$\begin{array}{lr}\text { kedalaman } & \text { gempa } \\ \text { tremornya. Serta } & \text { mampu } \\ \text { menjelaskan } & \text { secara } \\ \text { matematis mengenai } & \text { tremor } \\ \text { sumber tremor } & \text { trang } \\ \text { vulkanik gunung Semeru } \\ \text { dengan pengamatan yang } \\ \text { detail. }\end{array}$

\section{REFERENSI}

1. Dinas Energi dan Sumber Daya Mineral Propinsi Jawa Timur. 2010. G. Semeru. Surabaya: Pemerintah Propinsi Jawa Timur.

2. Gottschammer, E. 1998. Seismic Signal at Bromo Volcano, Indonesia . Germany: University of Karlsruhe.

3. Julian, R. B., 1994. Volcanic Tremor: Nonlinier Exicitation by Fluid Flow, Journal of Geophysical Research, 99(B6): 11859-11877.

4. Kirbani, S. B., Fadeli, A., Wahyudi, Iman, S., dan Ari, S., 1992. Laporan Penelitian Studi Pendahuluan Seismisitas Gunung

5. Semeru, Jawa Timur. FPMIPA, UGM, Yogyakarta, Indonesia.

6. Sutawidjaja, I., S., Wahyudin, D., and Kusdinar, E. 1996. Geological map of Semeru volcano, East Java (1:50,000 scale). Direktorat Vulkanologi, VSI. Bandung.

7. Van Bemmelen. 1949. The geology of Indonesia and adjacent achipelago. Government Printing Office, The Hague, pp 150

8. VSI. (2013, Agustus 13). Gunung Semeru [Online]. Diakses dari VSI ESDM Web site:http://www.vsi.esdm.go.i $\mathrm{d} /$ index.php/gunungapi/datadasar-gunungapi/211-gsemeru?start $=2$.

9. Welayatur, R. 2013. Analisis Fisis Aktivitas Gunung Talang berdasarkan Karakteristik Spektral dan Estimasi Hiposenter Gempa Vulkanik . Universitas Brawijaya, Malang.

10. Yatini. 1995. Analisis Tremor Harmonik Sebelum Letusan 3 Februari 1994 Untuk Memperoleh Dimensi dan Sistem Volkanik G. Semeru. Thesis S-2 Program Studi Geofisika Terapa, Pasca Sarjana, ITB, Bandung. 